\title{
Pengembangan Media Busy Book dalam Pembelajaran Motorik Halus Anak Usia 4-5 Tahun
}

\author{
Qonitah Faizatul Fitriyah ${ }^{\varpi_{1}}$, Sigit Purnama1 ${ }^{1}$ Yudha Febrianta' ${ }^{1}$, Suismanto' ${ }^{1}$, Hafidh 'Aziz' \\ Pendidikan Islam Anak Usia Dini, Universitas Islam Negeri Sunan Kalijaga Yogyakarta(1) \\ DOI: $10.31004 /$ obsesi.v6i2.789
}

\begin{abstract}
Abstrak
Penggunaan media dalam proses pelaksanaan pembelajaran dapat menjadi solusi dalam keefektifan perkembangan motorik halus pada anak dengan jenis $\mathrm{RnD}$ atau Reserach and Development menggunakan model Borg and Gall, teknik anallisis data diperoleh data hasil validasi instrumen berupa data deskriptif oleh para ahli, yitu ahli media, ahli materi dan user. Hasil ini adalah media busy book mendapatkan penilaian dari ahli materi yang menunjukkan kriteria sangat baik menunjukkan presentase $82 \%$. Skor oleh ahli media dengan kriteria sangat baik dengan presentase $92 \%$. Uji coba lapangan produk media busy book diujikan kepada 8 peserta didik ant class (Kelompok A) dan direspon oleh guru kelas serta pendidik sebagai user di TK Ceria Demangan Yogyakarta, hasil dari tahap uji coba menunjukkan 50\% anak didik mendapatkan kategori "Sangat Baik" dan 50\% anak didik mendapatkan kategori "Baik". Kesimpulannya adalah media bermain busy book layak digunakan.
\end{abstract}

Kata Kunci: media busy book; motorik halus; anak usia dini.

\begin{abstract}
Using media in process implementing learning can help solution of fine motoric development in children. In this research, we developed busy book media which aims to train fine motor skills in children aged 4-5 years. Method used is Research and Development (RnD) using Borg and Gall model, the analysis technique obtained data from instrument validation in the form of descriptive data carried out by material experts, media experts and users and converted into quantitative data with a scale of 5 . The results showed that the busy book media received an assessment from material experts with the criteria very good with a percentage $82 \%$. Assessment by media experts with the criteria very good with a percentage $92 \%$. Field trials of busy book media products were tested on 8 ant class students (Group A) and were responded to by class teachers and educators as users at Kindergarten Ceria Demangan Yogyakarta, the results of the trial phase showed $50 \%$ of students got the "Very Good" category and 50\% of students get the "Good" category. So, cocnluded that the busy book is suitable for learning fine motoric skills in children aged 4-5 years.
\end{abstract}

Keywords: busy book media; fine motor skills; early childhood.

Copyright (c) 2021 Qonitah Faizatul Fitriyah, Sigit Purnama, Yudha Febrianta, Suismanto, Hafidh 'Aziz

$\triangle$ Corresponding author:

Email Address : qonitah.fitriyaa@gmail.com (Yogyakarta, Indonesia)

Received 25 September 2020, Accepted 31 December 2020, Published 26 June 2021 


\section{PENDAHULUAN}

Kemampuan motorik cenderung diabaikan oleh beberapa pihak stimulan, seperti orangtua dan guru. Hal tersebut karena adanya faktor individu yang beranggapan bahwa aspek kognitif atau kemampuan berfikir pada anak memiliki makna yang lebih penting dibandingkan dengan kemampuan yang lainnya (Mustami'ah et al., 2011). Faktanya, anak usia dini sedang ada pada penting untuk memberikan stimulasi bagi pertumbuhan dan perkembangan. Pada rentang usia yang dialami oleh anak usia dini sangat menentukan, karena perkembangan kecerdasan pada masa ini sangat luar biasa, sehingga semua potensi yang ada pada anak perlu untuk di stimulasi agar anak mampu berkembang secara optimal.

Saat ini persyaratan untuk dapat memasuki jenjang selanjutnya atau dalam hal ini adalah untuk masuk dalam jenjang pendidikan dasar, anak harus mampu untuk melaksanakan tugas-tugas perkembangan selanjutnya, berkaitan dengan hal ini kemampuan untuk menulis, melukis, serta melakukan kegiatan sehari-hari seperti mengancingkan baju, menyikat gigi, atau mencuci tangan sangat memerlukan kemampuan motorik halus pada anak.

Sebelum perkembangan pada anak terbentuk, anak tidak berdaya namun kondisi pada anak tersebut akan cepat berubah (Hurlock, 2011). Terjadinya perubahan pada anak, awal perkembangan pada adalah perkembangan yang menunjukkan pengendalian gerakan kasar pada koordinasi yang melibatkan otot kecil. Sehingga, pada usia tersebut sangat penting untuk guru atau orangtua melatih serta memberikan stimulasi untuk aspek motorik halus berkembang secara ideal.

Selanjutnya, perkembangan motorik halus pada anak dapat mempengaruhi perkembangan-perkembangan yang lainnya seperti perkembangan kognitif (Pienaar et al., 2014), dan aktivitas fisik untuk menjalani kehidupan sehari-hari (Lubans, Morgan, Cliff, Barnett, \& Okely, 2010; Dubose, Mcmillan, Wood, \& Sisson, 2018). Maka perkembangan motorik halus pada anak perlu diperhatikan dengan seksama oleh orang-orang sekitar, khususnya orangtua dan guru. Selian itu guru dituntut untuk memiliki keterampilan pedagogi agar proses pembelajaran dapat lebih optimal (Pudyastuti \& Budiningsih, 2021; Fauziddin et al., 2021), utamanya dalam mengembangkan motorik halus anak.

Setiap anak lahir dengan potensi yang ada pada diri anak, yaitu potenso yang ada pada dasar manusia dan memiliki kaitannya dengan keyakinan (Trenggonowati \& Kulsum, 2018). Oleh karena itu, anak akan tumbuh dengan baik jika potensi dapat distimulasi dan ditumbuhkan dengan baik pula. Untuk membentuk serta mengembangkan potensi pada anak tersebut maka lingkungan keluarga dan lingkungan masyarakat sangat memiliki peran yang penuh di dalamnya.

Motorik halus merupakan kemampuan yang berintegrasi antara kinestetik, koordinasi mata dan tangan, motorik visual, tingginya koordinasi dan tingginya regulasi gaya presisi (Feder \& Majnemer, 2007; Inayat, Yunus, \& Adnan, 2010). Kemampuan motorik halus juga diartikan menjadi keterampilan yang memerlukan koordinasi otot kecil pada manusia (Heri, 2012). Contoh keterampilan motorik halus pada anak adalah menggunting, meronce, menulis, mewarnai, dan aktivitas lain (Matarma et al., 2020).

Motorik halus pada anak dapat dikembangkan dengan memanfaatkan beberapa media, seperti dalam penelitian Rakihmawati, Lestari, dan Hartati dengan menggunakan media kirigami untuk melihat adanya pengaruh yang signifikan. Research tersebut menghasilkan media kirigami dapat digunakan menjadi rangsangan bagi motorik halus anak (Rakimahwati et al., 2018). Selain penelitian tersebut, terdapat media lain yang dapat dimanfaatkan untuk menstimulasi perkembangan motorik halus anak yaitu media konkret kolase, dalam penelitian Misiyanti, Parmiti dan Wirya menghasilkan media konkret dengan kolase dapat memberikan peningkatan pada motorik halus anak serta mampu meningkatkan kreativitas pada anak (Misiyanti et al., 2018).

Busy Book sendiri merupakan merupakan media bermain yang berbentuk buku dengan berbahan dasar kain flanel, di dalam buku tersebut terdapat variasi tambahan 
dengan menggunakan zipper (risleting), kancing baju, kain perca, dan variasi-variasi yang lainnya. Desain busy book sendiri memberikan nuansa yang warna-warni sehingga menumbuhkan ketertatikan dan kesenangan pada anak dalam mengikuti pembelajaran.

Penelitian sebelumnya menunjukkan bahwa media bermain busy book dapat meningkatkan kemampuan kecerdasan visual-spasial pada anak (Annisa et al., 2017), kemampuan membaca dan menghitung pada anak (Ulfa \& Rahmah, 2017; Nilmayani et al., 2017; Rakimahwati et al., 2018), serta mampu untuk meningkatkan kemamuan pada kosakata anak (Mufliharsi, 2017). Namun, belum ada penelitian yang mengembangkan media bermain busy book yang dapat digunakan, sehingga berdasarkan pemaparan di atas peneliti mendesain sebuah media bermain busy book untuk meningkatkan kemampuan anak pada aspek motorik halus di usia 4-5 tahun.

Lembaga sekolah TK Ceria Demangan, peneliti menemukan bahwa aspek motorik halus pada anak ant class (TK A) usia 4-5 tahun, memiliki aktivitas yang begitu-begitu saja dalam arti kurang dalam memanfaatkan media pembelaran. Pengembangan media bermain busy book dapat bermanfaat untuk memberikan pembelajaran yang menyenangkan dan tidak dipaksakan dalam implementasi pembelajarannya.

\section{METODOLOGI}

Penelitian ini adalah pengembangan suatu product yang memiliki sifat kebaruan atau penyempurnaan produk yang dahulu sudah diciptakan sehingga dapat dipertanggungjawabkan (Saondi, 2012). Produk ini adalah sebuah desain media yang dipakai untuk proses belajar mengajar dalam bentuk visual APE atau alat permainan edukatif busy book. Alasan menggunakan jenis penelitian $R n D$ adalah kurangnya media bermain dijadikan sebagai stimulasi untuk kemampuan pada motorik halus anak, sehingga peneliti mengembangkan media bermain. Lokasi pelaksanaan penelitian ini dilaksanakan di TK Ceria Demangan, Sleman, Yogyakarta, kemudian diuji cobakan pada anak anak didik ant class. Partisipan ada 8 anak dengan karakteristik kemampuan motorik halus masih berkembang.

Instrumen pengumpulan data dan pengembangan ini adalah lembar skala yang berisi pertanyaan terkait dengan kelayakan produk media bermain busy book yang diadaptasi dari lembar skala penilaian kelayakan media bermain anak dari beberapa penelitian relevan, sebelum instrumen dibagikan kepada user instrumen di yang telah di validasi ahli.

Langkah pengembangan media dalam penelitian ini adalah (Sugiyono, 2015) (1) koleksi data (2) rencana (3) pengembangan awal pada product, (4) uji coba, (5) perbaikan. Prosedur pengembangan yang dipakai oleh peneliti tidak mencakup seluruh langkahlangkahnya, karena penyesuaian dengan tujuan pada penelitian dalam mengembangkan product busy book. Data dikumpulkan berupa ketersediaan media di TK Ceria Demangan.

Tahapan penelitian dan pengumpulan data, merupakan tahap pertama dari penelitian pengembangan untuk memperoleh informasi mengenai penelitian dan pengembangan yang akan peneliti lakukan. Tahap perencanaan menetapkan indikator dan kriteria penilaian pada setiap lembar aktivitas media bermain busy book, dan menetapkan menetapkan komponen media bermain berupa jumlah lembar aktivitas, bahan dasar media bermain, tema dari media bermain, warna dan desain media bermain. Tahap pengembangan produk awal, menyusun media bermain busy book sesuai dengan standar rancangan alat yang telah ditetapkan, kemudian media di validasi oleh para ahli untuk direvisi dan diberi masukan. Produk media bermain busy book selanjutnya diujikan pada 8 peserta didik ant class (TK A) dan direspon oleh guru kelas serta pendidik PAUD sebagai user. Revisi Produk, produkyang sudah dikembangkan kemudian direvisi yang sudah diperoleh saat uji coba lapangan awal.

Teknik analisis data dilakukan dengan cara pengisian skala penilaian kualitas produk media busy book yang dilakukan oleh para ahli dan user. Hasil penilaian data deskriptif yang 
selanjutnya diubah kuantitatif dengan skala 5, kemudian ditabulasi dan dianalisis untuk menentukan kelayakan dari product.

Dalam penilaian validasi produk yang dilakukan oleh para ahli, serta pendidik PAUD yang juga berperan sebagai user. Diperoleh data pada Tabel 1.

Tabel 1. Instrumen Penilaian Produk Media Busy Book

\begin{tabular}{clcl}
\hline No & \multicolumn{1}{c}{ Aspek } & Jumlah Kriteria & \multicolumn{1}{l}{ Nomor } \\
\hline $\mathbf{1}$ & Materi lengkap & 2 & 1,2 \\
\hline $\mathbf{2}$ & Materi akurat & 2 & 3,4 \\
\hline $\mathbf{3}$ & Keluasan materi & 2 & 5,6 \\
\hline $\mathbf{4}$ & Kejelasan materi & 4 & $7,8,9 \& 10$ \\
\hline $\mathbf{5}$ & Isi media & 6 & $11,12,13,14,15, \& 16$ \\
\hline $\mathbf{6}$ & Penciptaan desain & 4 & $17,18,19 \& 20$ \\
\hline $\mathbf{7}$ & Penyajian & 5 & $21,22,23,24 \& 25$ \\
\hline
\end{tabular}

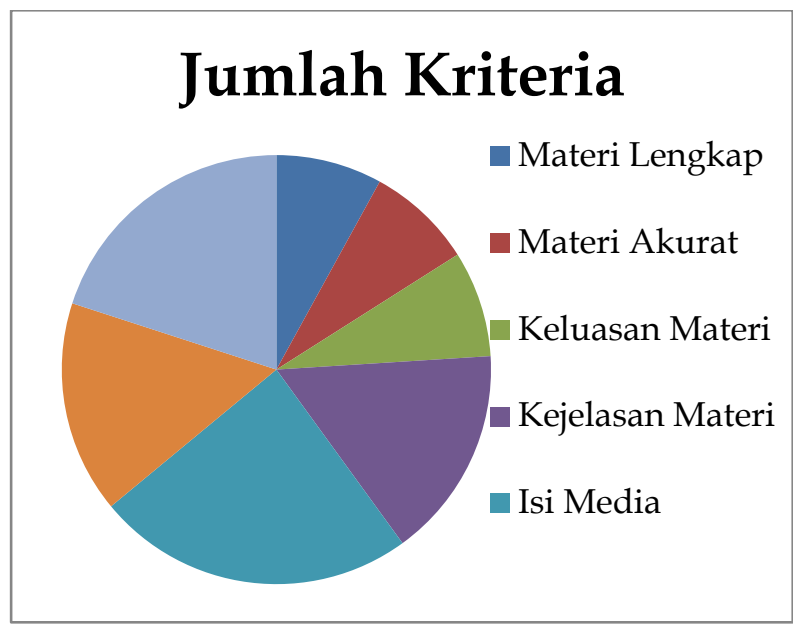

\section{Gambar 1. Kisi-kisi Instrumen Penilaian Kualitas Produk Media Busy Book}

Prosedur teknik analisis data ini adalah hasil penilaian oleh dosen ahli dan user dengan skala 5 sesuai dengan aturan pemberian skor pada tabel 2.

Tabel 2. Skor 5

\begin{tabular}{ccccc}
\hline No & Kriteria & Skala & Interval rata-rata skor & Kesesuaian 100\% \\
\hline $\mathbf{1}$ & Sangat Baik & 5 & $4,2<\mathrm{X}$ & $81 \%-100 \%$ \\
\hline $\mathbf{2}$ & Baik & 4 & $3,4<\mathrm{X}<4,2$ & $61 \%-80 \%$ \\
\hline $\mathbf{3}$ & Cukup & 3 & $2,6<\mathrm{X}<3,4$ & $41 \%-60 \%$ \\
\hline $\mathbf{4}$ & Kurang & 2 & $1,8<\mathrm{X}<2,6$ & $21 \%-40 \%$ \\
\hline $\mathbf{5}$ & Sangat Kurang & 1 & $\mathrm{X}<1,8$ & $\mathrm{X}<21 \%$ \\
\hline
\end{tabular}

\section{HASIL DAN PEMBAHASAN}

Desain Produk

Media busy book dibuat dengan menarik dan warna-warni sehingga memberikan kesan yang menyenangkan pada anak ketika menggunakan media pembelajaran tersebut.. Dalam buku tersebut terdapat 8 lembar aktivitas permainan. Masing-masing lembar busy book memiliki tujuan indikator acuan aktivitas sesuai dengan indikator seperti pada Tabel 4.

Masing-masing lembar dalam media pembelajaran busy book memiliki aktivitas yang berbeda-beda. Lembar pertama pada media busy book ini adalah memasukkan tali pada benang pita yang disusun rapi dan proporsional sesuai dengan kemampuan pada anak, 
lembar kedua bermain bug and child menarik zipper serta merekatkan bug pada tempat yang sudah disediakan, lembar ketiga memancing ikan dengan mengaitkan magnet pada pancing dan mulut pada ikan, lembar keempat merekatkan bentuk-bentuk geometri pada tempat yang sudah disiapkan, lembar kelima membuat rantai, lembar keenam melepaskan dan memasang gasper kemudian bermain menggunakan gajah sirkus, lembar ketujuh bermain menggunakan monyet dan pisang, dan lembar terakhir adalah bermain boneka jari. Gambar 1 - 5 merupakan gambaran media bermain busy book.

\section{Tabel 4. Indikator Acuan Aktivitas Media Motorik Halus}

\begin{tabular}{ll}
\hline No & \multicolumn{1}{c}{ Indikator } \\
\hline 1 & Membuat garis lurus dan miring \\
2 & Mengenal macam-macam bentuk \\
3 & Koordinasi antara mata dengan tangan menciptakan gerakan kompleks \\
4 & Berekspresi dan berkarya menggunakan media \\
5 & Kontrol tangan dengan otot halus \\
\hline
\end{tabular}



Gambar 1. Sampul Busy Book

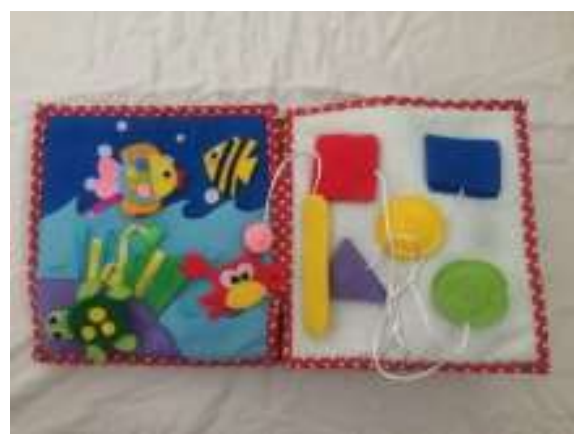

Gambar 3. Lembar 3 dan 4

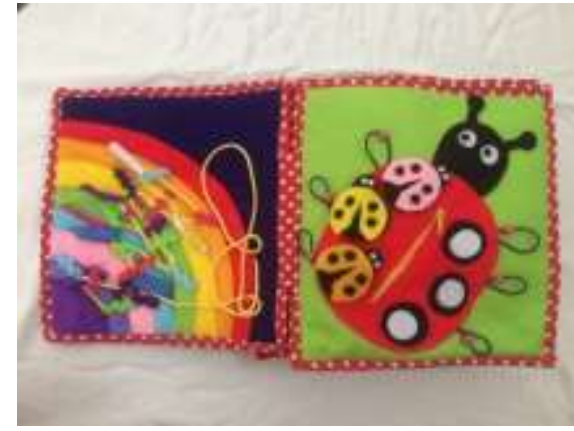

Gambar 2. Lembar 1 dan 2



Gambar 4. Lembar 5 dan 6



Gambar 5. Lembar 7 dan 8 


\section{Analisis Kelayakan Ahli}

Tabel 5. Penilaian Validasi oleh Ahli Materi Busy Book

\begin{tabular}{llcccc}
\hline No & Aspek Penilaian & Skor & $\begin{array}{c}\text { Skor Maks. } \\
\text { Ideal }\end{array}$ & $\begin{array}{c}\text { Presentase } \\
\text { Keidealan }(\%)\end{array}$ & Kat. \\
\hline 1. & Kelengkapan Materi & 8 & 10 & 80 & B \\
2. & Akurasi Materi & 8 & 10 & 80 & B \\
3. & Kedalaman dan & 9 & 10 & 90 & SB \\
& Keluasan Materi & & & & SB \\
4. & Kejelasan Materi & 17 & 20 & 85 & SB \\
\hline
\end{tabular}

Tabel 6. Penilaian Validasi oleh Ahli Media Busy Book

\begin{tabular}{llcccc}
\hline No & Aspek Penilaian & Skor & Skor Maks. Ideal & Presentase Keidealan (\%) & Kat. \\
\hline 1. & Isi Media & 29 & 30 & 96,7 & SB \\
2. & Penciptaan Desain & 17 & 20 & 85 & SB \\
3. & Penyajian Presentasi & 23 & 25 & 92 & SB \\
\hline Total & 69 & 75 & 92 & SB \\
\hline
\end{tabular}

Berdasarkan hasil dari validasi yang diperoleh sebagaimana pada tabel 5 dan 6, hasil validasi oleh ahli materi menunjukkan total skor 42 dari skor maksimal 50 dengan presentase keidealan $84 \%$ hal tersebut menunjukkan kategori sangat baik.

Berdasarkan hasil dari validasi oleh ahli media menunjukkan total 69 dari skor maksimal 75 dengan presentase keidealan 92\% hal tersebut menunjukkan kategori "Sangat Baik".

\section{Revisi Produk}

Revisi produk media busy book dengan catatan validasi, hasil revisi pada produk media bermain busy book pada penelitian ini disampaikan oleh ahli media media bermain busy book dibuatkan tas untuk media busy book

\section{Analisis Kelayakan User atau Pengguna}

Tabel 8. Hasil Penilaian Oleh User atau Pengguna

\begin{tabular}{|c|c|c|c|c|c|c|c|}
\hline \multirow[t]{2}{*}{ No } & \multirow[t]{2}{*}{ Aspek Penilaian } & \multicolumn{2}{|c|}{ Skor } & \multirow{2}{*}{$\begin{array}{c}\text { Skor Rata- } \\
\text { Rata }\end{array}$} & \multirow[t]{2}{*}{ Skor Maks. Ideal } & \multirow{2}{*}{$\begin{array}{c}\text { Presentase } \\
\text { Keidelaan } \\
(\%)\end{array}$} & \multirow[t]{2}{*}{ Ket. } \\
\hline & & I & II & & & & \\
\hline 1. & Kelengkapan Materi & 10 & 8 & 9 & 10 & 90 & SB \\
\hline 2. & Akurasi Materi & 9 & 9 & 9 & 10 & 90 & SB \\
\hline 3. & Kedalaman dan Keluasan Materi & 10 & 8 & 9 & 10 & 90 & SB \\
\hline 4. & Kejelasan Materi & 17 & 15 & 16 & 20 & 80 & B \\
\hline 5. & Isi Media & 30 & 27 & 28,5 & 30 & 95 & SB \\
\hline 6. & Penciptaan Desain & 20 & 17 & 18,5 & 20 & 92,5 & SB \\
\hline 7. & Penyajian Presentasi & 23 & 22 & 22,5 & 25 & 90 & SB \\
\hline Tot & & 119 & 106 & 112,5 & 125 & 90 & SB \\
\hline
\end{tabular}

Tabel tersebut menunjukkan hasil user diperoleh total skor 112,5 dari maksimal keidealan skor 125 dengan presentase $90 \%$ dengan kategori sangat baik. 


\section{Tahap Uji Coba}

Uji coba media pembelajaran busy book menggunakan uji coba terbatas (Sugiyono, 2015). Uji coba dilakukan kepada 8 anak di Ant Class A di TK Ceria Demangan dengan karakteristik yang berbeda-beda. Gambaran uji coba dapat dilihat pada gambar 6 dan 7 .

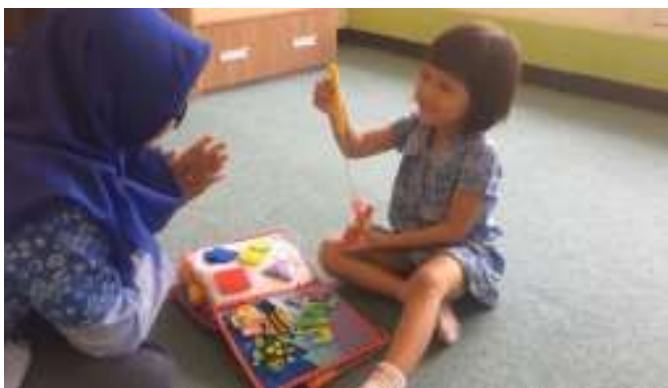

Gambar 6. Tahap Uji Coba 1

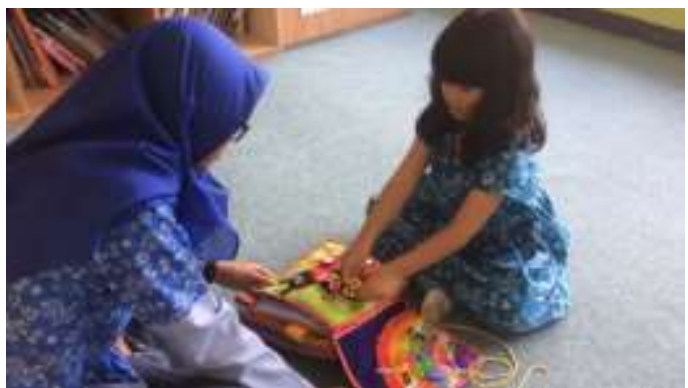

Gambar 7. Tahap Uji Coba 2

Tahap pertama dalam penggunaan media bermain busy book tersebut adalah berupa pengenalan media yang disampaikan oleh guru untuk peserta didik yang akan menggunakan media tersebut, mengenalkan terkait dengan komponen serta cara penggunaannya. User menggunakan busy book selama tiga dalam menerapkan pembelajaran motorik halus pada peserta didik.

Tabel 9 merupakan data penilaian kelayakan media busy book dalam pembelajaran motorik halus anak kelompok A oleh peserta didik.

Tabel 9. Hasil Penilaian Peserta Didik

\begin{tabular}{|c|c|c|c|c|c|c|c|c|c|c|c|c|c|c|}
\hline \multirow[t]{2}{*}{ No } & \multirow{2}{*}{$\begin{array}{c}\text { Nama } \\
\text { Peserta } \\
\text { didik }\end{array}$} & \multicolumn{8}{|c|}{ Lembar Aktivitas } & \multirow[t]{2}{*}{ Jml } & \multirow{2}{*}{$\begin{array}{l}\text { Skor } \\
\text { rata- } \\
\text { rata }\end{array}$} & \multirow{2}{*}{$\begin{array}{l}\text { Skor } \\
\text { Max. } \\
\text { Ideal }\end{array}$} & \multirow{2}{*}{$\begin{array}{c}\text { Presentase } \\
\text { Keidealan } \\
(\%)\end{array}$} & \multirow[t]{2}{*}{ Kat } \\
\hline & & 1 & 2 & 3 & 4 & 5 & 6 & 7 & 8 & & & & & \\
\hline 1. & Kenji & 11 & 18 & 15 & 10 & 6 & 17 & 15 & 10 & 102 & 12.7 & 115 & 88,7 & SB \\
\hline 2. & Sabina & 15 & 19 & 15 & 10 & 10 & 19 & 15 & 10 & 113 & 14.1 & 115 & 98,3 & SB \\
\hline 3. & Kirana & 7 & 15 & 11 & 10 & 7 & 14 & 14 & 8 & 86 & 10.7 & 115 & 74,8 & B \\
\hline 4. & Queeny & 10 & 17 & 12 & 10 & 7 & 15 & 12 & 8 & 91 & 11.4 & 115 & 79,2 & B \\
\hline 5. & Nena & 10 & 19 & 15 & 10 & 7 & 16 & 15 & 10 & 102 & 12.4 & 115 & 88,7 & B \\
\hline 6. & Brilli & 8 & 16 & 10 & 10 & 6 & 12 & 13 & 7 & 82 & 10.3 & 115 & 71,4 & B \\
\hline 7. & Noel & 11 & 19 & 14 & 10 & 10 & 19 & 11 & 8 & 102 & 12.7 & 115 & 88,7 & SB \\
\hline 8. & Samuel & 15 & 19 & 14 & 10 & 9 & 15 & 15 & 10 & 107 & 13.4 & 115 & 93,1 & SB \\
\hline Tot & & 87 & 142 & 106 & 80 & 62 & 127 & 110 & 71 & 785 & $\begin{array}{l}97.7 \\
\end{array}$ & 920 & 85,4 & SB \\
\hline
\end{tabular}

\section{Pembahasan}

Media pembelajaran busy book adalah media yang berbentuk buku dan memiliki sifat yang menarik karena warnanya yang memiliki banyak variasi dan aksesori, sehingga dapat memberikan ketertarikan pada anak untuk mau belajar. Busy book dikatakan layak digunakan dalam pembelajaran motorik halus anak 4-5 tahun. Kelayakan produk yang dinilai oleh para ahli dan tanggapan dari dua user (educator dan asisstant Ant Class) atau pengguna serta uji coba terbatas yang dilakukan terhadap penggunaan produk adalah a) ahli materi, validasi yang diperoleh menunjukkan total skor 42 dengan presentase keidealan $84 \%$ yang menunjukkan kategori "Sangat Baik". b) ahli media, validasi yang diperoleh menunjukkan total skor 69 dengan presentase keidealan 92\% hal tersebut menunjukkan kategori "Sangat Baik". c) Penilaian yang dilakukan oleh dua user atau pengguna menunjukkan total rata-rata skor 112,5 dengan presentase keidealan $90 \%$ sehingga menunjukkan kriteria "Sangat Baik". Validasi yang menyatakan bahwa busy book layak untuk digunakan serta menjadi suatu produk akhir untuk pembelajaran, karena sesuai dengan pencapaian persentase pada kelayakan media (Sugiyono, 2015). 
Motorik halus merupakan aspek yang harus diperhatikan dan di stimulasi mengingatkepentingan pada anak maka guru harus memililih metode dan menggunakan peralatan dengan baik agar anak mampu berkembang dengan optimal. Karena jika sejak dini anak mampu untuk mengkoordinasikan motorik halusnya dengan baik, maka perkembangan selanjutnya akan berlangsung dengan baik, begitu pula sebaliknya.

Berdasarkan hasil uji coba yang sudah dilakukan, media bermain busy book mampu membantu guru untuk mengefektifkan pembelajaran motorik halus pada anak dan lebih difokuskan pada gerakan-gerakan halus seperti kegiatan meletakkan dan memegang benda, menggunakan jari-jari tangan dimana keterampilan tersebut memerlukan koordinasi tangan yang baik dan dapat mempengaruhi perkembangan selanjutnya (Astini, Nurhasanah, \& Suarta, 2017).

Media pembelajaran busy book dapat digunakan dengan fleksibel dapat dibawa kemana saja. Bahan dan alat dalam media pembelajaran tersebut mudah didapat, aman, praktis, dan sederhana. Menurut mufliharsi media bermain busy book sebuah buku yang terbuat dari kain (Mufliharsi, 2017), menurut Ramadhani \& Sudarsini busy book adalah sebuah media yang memiliki manfaat untuk membantu memberikan stimulasi pada anak pada kemampuan befikir dan motorik halus (Ramadhani \& Sudarsini, 2018).

Pembelajaran motorik halus dengan menggunakan metode yang biasa saja dan terus menerus dilakukan dapat menimbulkan kebosanan pada anak didik (Sari, \& Aziz, 2018; Juniarti, 2019). Sehingga, penggunaan media busy book dalam pembelajaran motorik halus juga akan mengurangi kebosanan pada pelaksanaan pembelajaran motorik halus yang disampaikan kepada anak didik.

\section{SIMPULAN}

Media busy book sudah layak untuk digunakan dalam pembelajaran motorik halus pada anak usia 4-5 tahun. Kelayakan terhadap produk busy book tersebut didapatkan dari hasil validasi pengguna atau user serta uji coba terbatas penggunaan media. Validasi yang diperoleh dari ahli materi mendapatkan kualitas yang Sangat Baik (SB) keidealan sebesar $82 \%$. Validasi yang diperoleh dari ahli media diperoleh kualitas Sangat Baik (SB) keidealan sebesar 92\%. Uji coba terbatas terhadap produk Ant Class 8 anak. Dapat ditemukan bahwa busy book mampu melatih perkembangan motorik halus serta anak dapat berpartisipasi aktif dalam pembelajaran. Hasil penilaian pengguna atau user memperoleh kriteria Sangat Baik (SB) dengan presentase keidealan 90\%. Sehinnga, simpulan validasi menunjukkan bahwa media busy book layak diguakan untuk pembelajaran motorik halus pada anak usia 4-5 tahun.

\section{UCAPAN TERIMAKASIH}

Penulis ucapkan terimakasih kepada kampus UIN Sunan Kalijaga Yogyakarta serta terimakasih kepada kepala sekolah, educator, serta asisstant educator TK Ceria Demangan atas bantuan dan dukungan sampai terbitnya artikel ini.

\section{DAFTAR PUSTAKA}

DuBose, K. D., Gross McMillan, A., Wood, A. P., \& Sisson, S. B. (2018). Joint Relationship Between Physical Activity, Weight Status, and Motor Skills in Children Aged 3 to 10 Years. Perceptual and Motor Skills, 125(3), 478-492. https:// doi.org/10.1177/0031512518767008

Fauziddin, M., Mayasari, D., \& Rizki, L. M. (2021). Effective Learning for Early Childhood during Global Pandemic. Al-Ishlah: Jurnal Pendidikan, 13(1).

Feder, K. P., \& Majnemer, A. (2007). Handwriting development, competency, and intervention. Developmental Medicine and Child Neurology, 49(4), 312-317. https://doi.org/10.1111/j.1469-8749.2007.00312.x 
Heri Rahyubi. (2012). Teori-Teori Belajar dan Aplikasi Pembelajaran Motorik Anak Usia Dini. Nusa Media.

Hurlock, E. B. (2011). Psikologi Perkembangan: Suatu Pendekatan Sepanjang Rentang Kehidupan Edisi Kelima. In Jakarta : Erlangga (pp. 205-243). Erlangga.

Khalid, P. I., Yunus, J., \& Adnan, R. (2010). Extraction of dynamic features from hand drawn data for the identification of children with handwriting difficulty. Research in Developmental Disabilities, 31(1), 256-262. https://doi.org/10.1016/j.ridd.2009.09.009

Lubans, D. R., Morgan, P. J., Cliff, D. P., Barnett, L. M., \& Okely, A. D. (2010). Fundamental movement skills in children and adolescents: Review of associated health benefits. Sports Medicine, 40(12), 1019-1035. https://doi.org/10.2165/11536850-000000000$\underline{00000}$

Matarma, T., Lagström, H., Löyttyniemi, E., \& Koski, P. (2020). Motor Skills of 5-Year-Old Children: Gender Differences and Activity and Family Correlates. Perceptual and Motor Skills, 127(2), 367-385. https://doi.org/10.1177/0031512519900732

Misiyanti, N. W., Parmiti, D. P., \& Wirya, I. N. (2018). Penerapan metode demonstrasi berbantuan media konkret melalui kegiatan kolase untuk meninkatkan perkembangan motorik halus. E-Journal PG-PAUD, 2(1), 1-11. https://doi.org/10.23887/jippg.v2i3.15716

Mufliharsi, R. (2017). Pemanfaatan Busy Book pada Kosakata Anak Usia Dini di PAUD Swadaya PKK. Jurnal Metamorfosa.

Mustami'ah, D., Aquarisnawati, P., \& Riskasari, W. (2011). Motorik Halus Pada Anak Usia Prasekolah Ditinjau Dari Bender Gestalt of contents. Insan, 13(3), 1-8.

Nurlaili. (2019). Modul Pengembangan Motorik Halus Anak Usia Dini.

O Saondi. (2012). Penelitian Pendidikan. Deepublish.

Pienaar, A. E., Barhorst, R., \& Twisk, J. W. R. (2014). Relationships between academic performance, SES school type and perceptual-motor skills in first grade South African learners: NW-CHILD study. Child: Care, Health and Development, 40(3), 370-378. https://doi.org/10.1111/cch.12059

Pudyastuti, A. T., \& Budiningsih, C. A. (2021). Efektivitas Pembelajaran E-Learning pada Guru PAUD Selama Pandemic Covid-19. Jurnal Obsesi: Jurnal Pendidikan Anak Usia Dini, 5(2), 1667-1675. https:// doi.org/10.31004/obsesi.v5i2.873

Rakimahwati, R., Lestari, N. A., \& Hartati, S. (2018). Pengaruh Kirigami Terhadap Kemampuan Motorik Halus Anak di Taman Kanak-Kanak. Jurnal Obsesi : Jurnal Pendidikan Anak Usia Dini, 2(1), 98. https:// doi.org/10.31004/obsesi.v2i1.13

Ramadhani, S. N., \& Sudarsini. (2018). Media Quiet Book dalam Meningkatkan Keterampilan Memakai Baju Berkancing Bagi Tunagrahita. Ortopedagogia, 4(1), $12-$ 16.

Sai Tubtim, S. (2019). Using algae that produce biodiesel oil to treat wastewater of Industrial recycling plant. 229.

Sugiyono. (2015). Metode Penelitian Pendidikan Pendeketan Kualitatif, Kuantitatif, dan R\&D. Alfabeta.

Trenggonowati, D. L., \& Kulsum. (2018). Analisis Faktor Optimalisasi Golden Age Anak $\begin{array}{llll}\text { Usia. Journal Industrial } & \text { Servicess, }\end{array}$ https://doi.org/10.36055/jiss.v4i1.4088

Ulfah, A. A., \& Rahmah, E. (2017). Pembuatan dan Pemanfaatan Busybook dalam mempercepat kemampuan membaca untuk anak usia dini. Ilmu Informasi Perpustakaan Dan Kearsipan, 6(September), 28-37. 